\title{
Male carriers of balanced reciprocal translocations in Northeast China: sperm count, reproductive performance, and genetic counseling
}

\author{
H.G. Zhang, R.X. Wang, L.L. Li, W.T. Sun, H.Y. Zhang and R.Z. Liu \\ Center for Reproductive Medicine, Center for Prenatal Diagnosis, First Hospital, \\ Jilin University, Changchun, Jilin, China \\ Corresponding author: R.Z. Liu \\ E-mail: Irz410@126.com
}

Genet. Mol. Res. 14 (4): 18792-18798 (2015)

Received August 17, 2015

Accepted October 11, 2015

Published December 28, 2015

DOI http://dx.doi.org/10.4238/2015.December.28.28

ABSTRACT. Balanced chromosomal translocations in men can cause failure of spermatogenesis owing to meiotic impairment. Male carriers may exhibit normozoospermia, although clinical manifestations can include oligozoospermia or azoospermia, oligozoospermia or normozoospermia. Here, we reported the characteristics of balanced reciprocal translocations in men from northeastern China, and explored the relationship between sperm count and reproductive performance, to enable informed genetic counseling. The frequency of balanced reciprocal translocations was found to be $1.62 \%$. Semen analysis showed that $5.9 \%$ of male carriers had azoospermia, $43.1 \%$ had oligozoospermia, and $51.0 \%$ had normozoospermia. Of the 25 men with a balanced reciprocal translocation and azoospermia or oligozoospermia, chromosome 1 was the most commonly often involved in the translocation. However, in the 26 normozoospermic men with a balanced reciprocal translocation and normozoospermia, chromosome 3 was most commonly implicated. Fifty percent of men with a balanced reciprocal translocation conceived a pregnancy that went to term. Our data suggest that of all chromosomes, 
chromosomes 1 and 3 are the most commonly involved chromosomes in balanced reciprocal such translocations in northeastern Chinese men. Karyotype analysis should be performed for men with azoospermia, oligozoospermia, and those in couples having suffered recurrent miscarriages. Natural conception should be discussed during genetic counseling for male carriers of balanced chromosomal translocations with normozoospermia.

Key words: Sperm count; Balanced translocation; Genetic counseling; Reproductive performance

\section{INTRODUCTION}

Balanced chromosomal translocations are often identified as the a cause of infertility (Vozdova et al., 2013). They found in the karyotypes of $9.2 \%$ of couples with recurrent miscarriages (Vozdova et al., 2012), and in approximately $1 \%$ of infertile men. In addition, such translocations are more common in azoospermic than in oligozoosperic men (Kara et al., 2014).

It is well known that chromosomal translocations in men can cause failure of spermatogenesis owing to meiotic impairment (Kara et al., 2014). The effects of these genetic abnormalities are dependent on whether the reciprocal translocation is present in a balanced or unbalanced forms. Balanced forms exert no phenotypic effect on the carriers besides a possible show variable influence on carrier sperm counts, which can rangeing from normal counts to low counts (oligozoospermia), or even demonstrate a total absence of sperm in the ejaculate (azoospermia) (Venkateshwari et al., 2011). The functionality of genes at breakpoints, including genes those with a specific roles in spermatogenesis, may be altered. This may causing defective spermtogenesis sperm production and resulting in the abnormalities seen on observed during semen analysis (Olesen et al., 2001; Olesen et al., 2001; Ching et al., 2012 ).

Recently, several studies have reported that the natural pregnancy success rates of natural pregnancies in for couples in which the male partner carries a translocation carried translocations ranges from 30 to $70 \%$ ( Ozawa et al., 2008). Flynn et al. (2014) reported a cumulative live birth rate of $64.3 \%$ for couples having experienced repeated miscarriage and in which the male or either partner had a chromosomal anomaly and who had experienced repeated miscarriage. This suggests that continuing attempts to conceive naturally further attempts at natural conception is a viable option for successful pregnancy. Balanced translocations can be transmitted through the generations; therefore, most familial cases are to be of this kind and phenotypically normal, with balanced rearrangements (Kim et al., 2011).

However, reproductive outcome studies of involving such couples are limited, and the risk of miscarriage because of an unbalanced chromosomal aberration remains unknown. Most investigations have reported that in couples with suffering recurrent pregnancy loss, the number of women carrying with balanced chromosomal aberrations significantly exceeds of men (Kochharand Ghosh, 2013). One proposed mechanism explanation for contributing to these higher incidence of female translocation carriers is that only one ovum matures each month. Male carriers release millions of sperm in every ejaculation, and thus pre-zygotic selection against unbalanced gametes may be more effective in men (Kochhar et al., and Ghosh, 2013).

The present study aimed to report the relationship between sperm count and reproductive outcome in men from northeastern China carrying balanced reciprocal translocations. The implications of this association for genetic counseling are considered. 


\section{MATERIAL AND METHODS}

\section{Patients}

Between July 2010 and January 2014, 3148 men who were with infertility or receiving genetic counseling were recruited from outpatients of the Centre for Reproductive Medicine, First Hospital of Jilin University, Changchun, China. All patients underwent a thorough physical examination and a semen analysis, and blood samples from patients were stored for cytogenetic evaluation. Patients were defined as having oligozoospermia if their last three semen samples (taken at intervals of 1-3 weeks) had sperm counts of contained <less than $20 \times 10^{6} \mathrm{sperm} / \mathrm{mL}$, or azoospermia if no sperm were found in the ejaculate after centrifugation.

\section{Cytogenetic analysis}

Peripheral blood $(0.5 \mathrm{~mL})$ from all patients was collected from all patients in sterile tubes containing $30 \mathrm{U} / \mathrm{mL}$ heparin and inoculated aseptically into lymphocyte culture solution (Yishengjun, Guangzhou Baidi Biotech, Guangzhou, China). Cultures were incubated at $37^{\circ} \mathrm{C}$ for $72 \mathrm{~h}$ and before being treated with $20 \mu \mathrm{g} / \mathrm{mL}$ colcemid for $1 \mathrm{~h}$. G-banding of metaphase chromosomes and karyotype analysis were performed according to our previously published methods (Zhang et al., 2015).

\section{Pregnancy outcome}

Information regarding pregnancy outcomes was obtained from hospital records or a questionnaire completed during follow-up visits by the physician who attended the delivery.

\section{RESULTS}

Of the 3148 men studied, $51(1.62 \%)$ carried a balanced reciprocal translocation. The average age of the patients was $32.82 \pm 5.09$ years, (rangeing from 22 to 46 years). Semen analysis showed that three patients $(5.9 \%)$ with balanced reciprocal translocations had azoospermia, 22 (43.1\%) had oligozoospermia, and 26 (51.0\%) had normozoospermia.

Characteristics of reciprocal translocation carriers with exhibiting oligozoospermia or azoospermia are shown in Table 1. No full-term pregnancies were achieved for these carriers resulted from this group. Of the 22 oligozoospermic cases, two produced spontaneous abortions. Among the 25 carriers of a balanced reciprocal translocations with oligozoospermia or azoospermia, chromosomes $1(\mathrm{~N}=10)$ and $15(\mathrm{~N}=4)$ were the most commonly involved. chromosome $(\mathrm{N}=10)$, followed by chromosome $15(\mathrm{~N}=4)$.

Details of the normozoospermic reciprocal translocation carriers are shown in Table 2. Of these 26 men, 12 (46.1\%) conceived full-term natural pregnancies, and in one case an elective termination was performed $(3.85 \%)$. Thirteen cases $(50 \%)$ had a history of recurrent spontaneous abortions. Nine of the $26(34.6 \%)$ cases had no previous adverse pregnancy obstetric history and produced natural first pregnancies resulting in healthy children. Chromosomes 3 (N $=8), 1(\mathrm{~N}=5)$, and $5(\mathrm{~N}=5)$ were those most commonly involved translocated chromosome in normozoospermic cases. 
Table 1. Characteristics of reciprocal translocation carriers with oligozoospermia or azoospermia. No full termpregnancies resulted from this group.

\begin{tabular}{|c|c|c|c|}
\hline Patient number & Karyotype & Sperm count & Pregnancy outcome \\
\hline 1 & $46, \mathrm{XY}, \mathrm{t}(1 ; 10)(\mathrm{q} 21 ; \mathrm{p} 12)$ & AS & $\mathrm{N}$ \\
\hline 2 & $46, X Y, t(5 ; 21)(q 13 ; p 12)$ & AS & $\mathrm{N}$ \\
\hline 3 & $46, \mathrm{XY}, \mathrm{t}(\mathrm{Y} ; 16)(\mathrm{q} 11 ; \mathrm{p} 13)$ & AS & $\mathrm{N}$ \\
\hline 4 & $46, X Y, t(1 ; 21)(q 12 ; p 11.2)$ & os & $\mathrm{N}$ \\
\hline 5 & $46, X Y, t(2 ; 13)(p 10 ; q 10)$ & OS & $\mathrm{N}$ \\
\hline 6 & $46, \mathrm{XY}, \mathrm{t}(13 ; 19)(q 12 ; \mathrm{p} 13)$ & os & $\mathrm{N}$ \\
\hline 7 & $46, \mathrm{XY}, \mathrm{t}(15 ; 17)(\mathrm{p} 12 ; \mathrm{q} 11)$ & os & $\mathrm{N}$ \\
\hline 8 & $46, X Y, t(1 ; 9)(\mathrm{p} 32 ; \mathrm{p} 24)$ & OS & $\mathrm{N}$ \\
\hline 9 & $46, X Y, t(1 ; 12)(q 42 ; q 13)$ & OS & $\mathrm{N}$ \\
\hline 10 & $46, \mathrm{XY}, \mathrm{t}(1 ; 18)(\mathrm{p} 22 ; \mathrm{q} 21)$ & os & $\mathrm{N}$ \\
\hline 11 & $46, \mathrm{XY}, \mathrm{t}(1 ; 20)(\mathrm{p} 13 ; \mathrm{p} 11.2)$ & os & $\mathrm{N}$ \\
\hline 12 & $46, X Y, t(10 ; 22)(q 22 ; q 13)$ & OS & $\mathrm{N}$ \\
\hline 13 & $46, X Y, t(6 ; 7)(q 25 ; p 14)$ & OS & $\mathrm{N}$ \\
\hline 14 & $46, \mathrm{XY}, \mathrm{t}(15 ; 18)(\mathrm{q} 13 ; \mathrm{p} 11)$ & os & $\mathrm{N}$ \\
\hline 15 & $46, X Y, t(17 ; 19)(p 13 ; p 13)$ & os & $\mathrm{N}$ \\
\hline 16 & $46, X Y, t(1 ; 12)(p 34 ; q 13)$ & OS & $\mathrm{N}$ \\
\hline 17 & 46,XY,t(1;14)(p36;q24) & OS & $\mathrm{N}$ \\
\hline 18 & $46, X Y, t(2 ; 15)(p 11.2 ; q 15)$ & os & $\mathrm{N}$ \\
\hline 19 & $46, \mathrm{XY}, \mathrm{t}(4 ; 11)(\mathrm{q} 25 ; \mathrm{q} 21)$ & os & $\mathrm{N}$ \\
\hline 20 & $46, X Y, t(10 ; 19)(q 24 ; q 13)$ & OS & SA \\
\hline 21 & $46, Y, t(X ; 9)(q 13 ; q 13.1)$ & os & $\mathrm{N}$ \\
\hline 22 & $46, X Y, t(1 ; 3)(p 22 ; p 13)$ & OS & $\mathrm{N}$ \\
\hline 23 & $46, X Y, t(1 ; 4)(p 34 ; q 32)$ & os & SA \\
\hline 24 & $46, \mathrm{XY}, \mathrm{t}(10 ; 15)(\mathrm{p} 11 ; \mathrm{q} 11)$ & os & $\mathrm{N}$ \\
\hline 25 & $46, \mathrm{XY}, \mathrm{t}(11 ; 22)(\mathrm{q} 25 ; \mathrm{q} 13)$ & os & $\mathrm{N}$ \\
\hline
\end{tabular}

$\mathrm{AS}=$ azoospermia; $\mathrm{OS}=$ oligozoospermia; $\mathrm{SA}=$ spontaneous abortion; $\mathrm{N}=$ no pregnancy prior to use ofassisted reproductive technology.

Table 2. Characteristics of reciprocal translocation carriers with normozoospermia.

\begin{tabular}{|c|c|c|c|}
\hline Patient number & Patient karyotype & Obstetric history & Pregnancy outcomes \\
\hline 26 & $46, \mathrm{XY}, \mathrm{t}(1 ; 10)(\mathrm{p} 31.2 ; \mathrm{q} 26)$ & SA, SA, SA, SA & $\mathrm{N}$ \\
\hline 27 & $46, \mathrm{XY}, \mathrm{t}(1 ; 11)(\mathrm{q} 42 ; \mathrm{q} 21)$ & SA, SA, SA & $\mathrm{N}$ \\
\hline 28 & $46, X Y, t(1 ; 12)(q 42 ; q 13)$ & SA, SA, & $\mathrm{N}$ \\
\hline 29 & $46, X Y, t(3 ; 15)(q 21 ; q 22)$ & SA, SA, SA & $\mathrm{N}$ \\
\hline 30 & $46, X Y, t(3 ; 17)(q 25 ; q 23)$ & SA, SA, SA, SA & $\mathrm{N}$ \\
\hline 31 & $46, X Y, t(3 ; 20)(q 12 ; q 13)$ & SA, SA & $\mathrm{N}$ \\
\hline 32 & $46, X Y, t(3 ; 6)(q 21 ; q 25)$ & SA, SA, SA, SA & $\mathrm{N}$ \\
\hline 33 & $46, \mathrm{XY}, \mathrm{t}(3 ; 7)(\mathrm{p} 23 ; \mathrm{q} 21.2)$ & SA, SA, SA & $\mathrm{N}$ \\
\hline 34 & $46, X Y, t(4 ; 14)(q 25 ; q 24)$ & SA, SA, & $\mathrm{N}$ \\
\hline 35 & $46, X Y, t(4 ; 22)(q 35 ; q 11.2)$ & $S A, S A, S A, S A$ & $\mathrm{~N}$ \\
\hline 36 & $46, \mathrm{XY}, \mathrm{t}(5 ; 18)(\mathrm{p} 15 ; \mathrm{q} 11.2)$ & SA, SA, SA & $\mathrm{N}$ \\
\hline 37 & $46, \mathrm{XY}, \mathrm{t}(6 ; 8)(\mathrm{p} 21 ; \mathrm{q} 24)$ & SA, SA, SA & $\mathrm{N}$ \\
\hline 38 & $46, X Y, t(7 ; 10)(q 22 ; p 13)$ & SA, SA & $\mathrm{N}$ \\
\hline 39 & $46, \mathrm{XY}, \mathrm{t}(10 ; 19)(\mathrm{q} 24 ; \mathrm{p} 13.1)$ & SA & $\mathrm{T}[46, \mathrm{XX}, \mathrm{t}(10 ; 19)(\mathrm{q} 24 ; \mathrm{p} 13.1) p a t]$ \\
\hline 40 & $46, \mathrm{XY}, \mathrm{t}(5 ; 11)(\mathrm{p} 14 ; \mathrm{p} 15)$ & ET $(47, \mathrm{XX},+21)$ & $\mathrm{T}[46, \mathrm{XY}, \mathrm{t}(5 ; 11)(\mathrm{p} 14 ; \mathrm{p} 15)$ pat $]$ \\
\hline 41 & $46, X Y, t(5 ; 20)(q 13 ; q 12)$ & ET $[47, X X,+21, t(5 ; 20)(q 13 ; q 12)]$ & $\mathrm{T}[46, \mathrm{XX}, \mathrm{t}(5 ; 20)(\mathrm{q} 13 ; \mathrm{q} 12)$ pat $]$ \\
\hline 42 & $46, X Y, t(5 ; 18)(p 13 ; p 11)$ & & ET $[46, X X, \operatorname{der}(18) t(5 ; 18)(p 13 ; p 11) p a t]$ \\
\hline 43 & $46, X Y, t(1 ; 22)(p 22 ; q 11)$ & & $\mathrm{T}[46, \mathrm{XX}, \mathrm{t}(1 ; 22)(\mathrm{p} 22 ; \mathrm{q} 11) \mathrm{pat})]$ \\
\hline 44 & $46, X Y, t(17 ; 19)(p 11 ; q 13)$ & & $\mathrm{T}[46, \mathrm{XY}, \mathrm{t}(17 ; 19)(\mathrm{p} 11 ; \mathrm{q} 13) \mathrm{pat}]$ \\
\hline 45 & $46, X Y, t(3 ; 19)(q 12 ; q 13)$ & & $\mathrm{T}[46, \mathrm{XY}, \mathrm{t}(3 ; 19)(\mathrm{q} 12 ; \mathrm{q} 13) \mathrm{pat}]$ \\
\hline 46 & $46, X Y, t(1 ; 13)(p 22 ; q 32)$ & & $\mathrm{T}[46, \mathrm{XX}, \mathrm{t}(1 ; 13)(\mathrm{p} 22 ; \mathrm{q} 32) \mathrm{pat}]$ \\
\hline 47 & $46, \mathrm{XY}, \mathrm{t}(3 ; 6)(\mathrm{q} 12 ; \mathrm{q} 27)$ & & $\mathrm{T}[46, \mathrm{XY}, \mathrm{t}(3 ; 6)(\mathrm{q} 12 ; \mathrm{q} 27)$ pat $]$ \\
\hline 48 & $46, X Y, t(3 ; 9)(q 21 ; q 22)$ & & $\mathrm{T}[46, \mathrm{XX}, \mathrm{t}(3 ; 9)(\mathrm{q} 21 ; \mathrm{q} 22) \mathrm{pat}]$ \\
\hline 49 & $46, X Y, t(5 ; 13)(q 13 ; q 12)$ & & $\mathrm{T}[46, \mathrm{XY}, \mathrm{t}(5 ; 13)(\mathrm{q} 13 ; \mathrm{q} 12)$ pat $]$ \\
\hline 50 & $46, \mathrm{XY}, \mathrm{t}(2 ; 11)(\mathrm{q} 33 ; \mathrm{q} 23)$ & & $\mathrm{T}(46, \mathrm{XX})$ \\
\hline 51 & $46, \mathrm{XY}, \mathrm{t}(4 ; 16)(\mathrm{q} 35 ; \mathrm{q} 22)$ & & $\mathrm{T}(46, \mathrm{XY})$ \\
\hline
\end{tabular}

$\overline{\mathrm{SA}}=$ spontaneous abortion; $\mathrm{N}=$ no pregnancy prior to use of assisted reproductive technology; $\mathrm{T}=$ term pregnancy; $\mathrm{ET}=$ elective termination. 


\section{DISCUSSION}

Balanced translocation carriers account for $0.08-0.3 \%$ of the general population (Kochhar et al., and Ghosh, 2013). Couples with balanced chromosome such translocations frequently experience recurrent miscarriage, and and male carriers often show altered semen quality (Vozdova et al., 2013). The reported incidence of balanced chromosomal translocations in couples with a history of spontaneous abortions ranges from 3 to $6 \%$ (Resim et al., 2013). A high prevalence of all chromosomal abnormality types of chromosomal abnormalities has been recorded in male $(4.29 \%)$ partners of infertile couples undergoing intracytoplasmic sperm injection, and with balanced reciprocal translocations being the most frequently found observed aberrations chromosomal abnormalities (0.98\%) (Braun-Falco et al., 2007). These translocations have been found in approximately $1 \%$ of infertile men and are more common in azoospermic than in oligozoospermic male individuals (Kara et al., 2014). In this study, the frequency of balanced reciprocal translocations in male patients from northeastern China receiving genetic counseling was $1.62 \%$.

A ten-fold increased incidence of structural chromosome abnormalities has been found reported in infertile male individuals (on average, $5.1 \%$ ) compared to the normal population $(0.5 \%)$. The sex chromosomes are implicated in $3.8 \%$ of such abnormalities anomalies, while involve the sex chromosomes and $1.3 \%$ of abnormalities involve the autosomes (Bache et al., 2004). Most balanced chromosomal aberrations are not associated with a clinical phenotype; however, in some patients they may disrupt gene structure (Olesen et al., 2001; Pernice et al., 2002; Bianco et al., 2011; Li et al., 2014). Ananthapur et al. (2014) reported the unusual non-Robertsonian translocation 46,XY,t(2;11)(p14;q21), found in an infertile oligozoospermic man with no clinical manifestations other than primary infertility.

In male balanced X-autosome translocation carriers, azoospermia is the most common pathology, although some cases of severe oligozoospermia have also been reported with severe oligozoospermia. The cause of spermatogenic failure in carriers of an X-autosome translocations is unknown, although spermatogenesis sperm production displays greater much more sensitivitye to disruption of meiosis disruption than oogenesis, owing to a number of meiotic cell-cycle checkpoints (Akbari et al., 2012). In this study, a carrier of one such translocation, 46,Y,t(X;9)(q13;q13.1), demonstrated oligozoospermia. Kochhar and Ghosh (2013) reported that among 16 male carriers of a structural chromosomal rearrangement, chromosome 4 was the most frequently involved. In the presentis study, however, chromosome 1 was found to be that most commonly affected among in the 25 men with a balanced reciprocal translocation and azoospermia or oligozoospermia. Among the 26 normozoospermic carriers, chromosome 3 was most commonly often involved.

In translocation carriers, abnormal semen parameters can serve as indicators of spermatozoa with defective chromatin and aneuploidy in translocation carriers (Vozdova et al., 2013). Vozdova et al. (2013) observed normal semen parameters characteristics were found in $30.8 \%$ of Robertsonian and $59.5 \%$ of reciprocal translocation carriers. In addition, they found the proportion of sperm with containing unbalanced chromosomes was to be $55.1 \%$ in men with reciprocal translocations carriers, but reported that this proportion value did not different between normospermic patients and those showing altered semen parameters. Significantly increased incidence of spermatozoa with defects in chromatin integrity and condensation, such as aneuploidy of chromosomes not involved in the translocation, and diploidy, were also found in translocation carriers exhibiting abnormal semen parameters. Moreover, normospermic men with reciprocal translocations carriers showed an increase in chromosome 13 disomy compared to control subjects (Akbari et al., 2012).

Carriers of completely balanced chromosomal translocations bear all the necessary a full 
complement of genetic information. Therefore, such individuals with balanced reciprocal translocations are clinically normal, and reciprocal translocations can be inherited (Keify et al., 2012). However, Ozawa et al. (2008) describe an increased risk of progeny with unbalanced karyotypes, causing disrupted meiotic segregation of their abnormal chromosomes, potentially resulting in infertility, miscarriage, stillbirth, or the conception of a child with congenital anomalies.

These aberrations principally occur by two mechanisms: unbalanced segregation of the chromosomes involved in the translocation during meiosis, and the occurrence of an interchromosomal effects (Godo et al., 2013). The prevalence of abnormal segregation depends on the specific chromosomes involved in the translocation, the localization of breaks, and the frequency of chiasmata (Vozdova et al., 2008). The incidence of chromosomally imbalance or aneuploid gametes may even vary between individual translocation carriers, even if where the same chromosomes are involved in the translocation (Vozdova et al., 2008). For carriers of balanced chromosomal translocations, in vitro fertilization accompanied by preimplantation genetic diagnosis (PGD) increases the chance of their fathering a healthy child (Vozdova et al., 2011).

Therefore, Ching et al. (2012) argue that genetics counselors are an indispensable part of infertility evaluation (Ching et al., 2012). For couples with balanced translocations, appropriate counseling is crucial for the understanding of suitable reproductive options. Prenatal testing and, alternatively, PGD are a recommended part of such counseling for carriers, as these patients are at increased risk of implantation failure, miscarriage, or delivery of affected offspring (Vozdova et al., 2013). Although it is likely that couples with a balanced translocation will at some point achieve a successful natural pregnancy is probable in couples with a balanced translocation, repeated miscarriages and terminations of abnormal fetuses are associated with psychological trauma and a significant physical burden (Chang et al., 2012).

In conclusion, chromosomes 1 and 3 were most commonly involved in balanced reciprocal translocations in men of northeastern China. Karyotype analysis should be performed for men with azoospermia, oligozoospermia, and in couples suffering recurrent miscarriages. Natural conception should be considered during genetic counseling for male carriers of balanced chromosomal translocations with normozoospermia.

\section{Conflicts of interest}

The authors declare no conflict of interest.

\section{ACKNOWLEDGMENTS}

We express our sincere gratitude to all the staff of the Genetics Laboratory, Center for Prenatal Diagnosis, First Hospital, Jilin University, for their excellent work. This work was supported by the National Natural Science Fund (\#81471515).

\section{REFERENCES}

Akbari MT, Behjati F, Pourmand GR, Asbagh FA, et al. (2012). Cytogenetic abnormalities in 222 infertile men with azoospermia and oligospermia in Iran: report and review. Indian J. Hum. Genet. 18: 198-203.

Ananthapur V, Avvari S, Veena K, Sujatha M, et al. (2014). Non-Robertsonian translocation t $(2 ; 11)$ is associated with infertility in an oligospermic man. Andrologia. 46: 453-455.

Bache I, Assche EV, Cingoz S, Bugge M, et al. (2004). An excess of chromosome 1 breakpoints in male infertility. Eur. J. Hum. Genet. 12: 993-1000. 
Bianco B, Christofolini D, Gava M, Mafra F, et al. (2011). Severe oligospermia associated with a unique balanced reciprocal translocation $\mathrm{t}(6 ; 12)(\mathrm{q} 23 ; \mathrm{q} 24.3)$ : male infertility related to $\mathrm{t}(6 ; 12)$. Andrologia. 43: 145-148.

Braun-Falco M, Schempp W, Nevinny-Stickel-Hinzpeter C and Köhn FM (2007). Azoospermia due to a unique de novo balanced reciprocal translocation (Y;1) (q12;q25). J. Androl. 28: 647 -651.

Chang EM, Han JE, Kwak IP, Yoon TKLee WS, et al. (2012). Preimplantation genetic diagnosis for couples with a Robertsonian translocation: practical information for genetic counseling. J. Assist. Reprod. Genet. 29: 67-75.

Ching CB, Ko E, Hecht B, Smith M, et al. (2012). Presentation and treatment of subfertile men with balanced translocations: the cleveland clinic experience. Curr. Urol. 6: 37-42

Flynn H, Yan J, Saravelos SH and Li TC (2014). Comparison of reproductive outcome, including the pattern of loss, between couples with chromosomal abnormalities and those with unexplained repeated miscarriages. J. Obstet. Gynaecol. Res. 40: 109-116.

Godo A, Blanco J, Vidal F and Anton E (2013). Accumulation of numerical and structural chromosome imbalances in spermatozoa from reciprocal translocation carriers. Hum. Reprod. 28: 840-849.

Kara M, Sen A, Cetin ES and Kargun K (2014). Chromosomal Translocation t (10;19) (q11.2;q13.4) in an Infertile Male. Eurasian J. Med. 46: 220-223.

Keify F, Zhiyan N, Mirzaei F, Tootian S, et al. (2012). Two novel familial balanced translocations $t(8 ; 11)(p 23 ; q 21)$ and $t(6 ; 16)$ (q26;p12) implicated in recurrent spontaneous abortion. Arch. Iran. Med. 15: 249-252.

Kim JW, Chang EM, Song SH, Park SH, et al. (2011). Complex chromosomal rearrangements in infertile males: complexity of rearrangement affects spermatogenesis. Fertil. Steril. 95: 349- 352.

Kochhar PK and Ghosh P (2013). Reproductive outcome of couples with recurrent miscarriage and balanced chromosomal abnormalities. J. Obstet. Gynaecol. Res. 39: 113-120.

Li L, Chen H, Yin C, Yang C, et al. (2014). Mapping breakpoints of a familial chromosome insertion (18,7) (q22.1; q36.2q21.11) to DPP6 and CACNA2D1 genes in an azoospermic male. Gene. 547: 43-49.

Olesen C, Hansen C, Bendsen E, Byskov AG, et al. (2001). Identification of human candidate genes for male infertility by digital differential display. Mol. Hum. Reprod. 7: 11-20.

Ozawa N, Maruyama T, Nagashima T, Ono M, et al. (2008). Pregnancy outcomes of reciprocal translocation carriers who have a history of repeated pregnancy loss. Fertil. Steril. 90: 1301-1304.

Pernice F, Mazza G, Puglisi D, Luppino MG, et al. (2002). Nonrobertsonian translocation $\mathrm{t}(6 ; 11)$ is associated with infertility in an oligoazoospermic male. Fertil. Steril. 78: 192-194.

Resim S, Kadioglu A, Akman T, Bayrak AG, et al. (2013). Balanced chromosomal translocation of chromosomes 6 and 7: a rare male factor of spontaneous abortions. Balkan Med. J. 30: 250- 252.

Venkateshwari A, Srilekha A, Begum A, Sujatha M, et al. (2011). De novo chromosomal translocation $\mathrm{t}(3 ; 5)(\mathrm{q} 13 ; \mathrm{q} 35)$ in an infertile man. Andrologia. 43: $428-430$.

Vozdova M, Oracova E, Horinova V and Rubes J (2008). Sperm fluorescence in situ hybridization study of meiotic segregation and an interchromosomal effect in carriers of $\mathrm{t}(11 ; 18)$. Hum. Reprod. 23: 581-588.

Vozdova M, Oracova E, Musilova P, Kasikova K, et al. (2011). Sperm and embryo analysis of similar t(7;10) translocations transmitted in two families. Fertil. Steril. 96: e66-70.

Vozdova M, Kasikova K, Oracova E, Prinosilova P, et al. (2012). The effect of the swim-up and hyaluronan-binding methods on the frequency of abnormal spermatozoa detected by FISH and SCSA in carriers of balanced chromosomal translocations. Hum. Reprod. 27: 930-937.

Vozdova M, Oracova E, Kasikova K, Prinosilova P, et al. (2013). Balanced chromosomal translocations in men: relationships among semen parameters, chromatin integrity, sperm meiotic segregation and aneuploidy. J. Assist. Reprod. Genet. 30: 391-405.

Zhang HG, Liu XY, Hou Y, Chen S, et al. (2015). Reproductive outcome of a case with familial balanced translocation $t(3 ; 6)$ : implications for genetic counseling. Genet. Mol. Res. 14: 2809-2815. 